\title{
Significance of histologic grading using visual analogue scale in chronic gastritis
}

\author{
Priyadarshini M M ${ }^{1}$, Gitanjali M. M. $^{2}$, Manjunatha $Y . A^{3}$ \\ ${ }^{1}$ Dr. Priyadarshini Monnappa, Kodagu Institute of Medical Sciences, India, ${ }^{2}$ Dr Gitanjali M.M., Assistant Professor, \\ ${ }^{3}$ Manjunatha Y. A, DM, WIMS, Waynad, Kerala 673577, India.
}

Corresponding Author: Dr. Gitanjali M.M, Email: piyadarsh@gmail.com

\begin{abstract}
Introduction: Helicobacter Pylori and its association with carcinogenesis has significantly changed the field, establishing new guidelines for the detection of it. Carcinogenicity of $\mathrm{H}$. Pylori necessitates grading the variables with visual analogue scale in accordance to Sydney system classification. The objectives of this study is to assess chronic gastritis and grade with visual analogue scale of Sydney classification. Methods: This is a prospective study of 3 years in which 50 gastric endoscopic mucosal biopsies were included in the study. Grading of the variables were done with reference to Sydney classification. Morphological changes in all cases were studied with special reference to atrophy, dysplasia, metaplasia, neutrophilic infiltration, lymphoid follicle formation, plasma cell infiltration \& malignant changes along with identification of $\mathrm{H}$. pylori. Results: Of the 50 cases studied for gastritis, 20 cases (44.4\%) had Chronic $\mathrm{H}$. pyloric gastritis followed by 18 cases (38.6\%) of chronic gastritis with nonspecific features. Evaluation for graded variables showed 41 cases of gastritis with chronic inflammation of which 22 cases showed H. Pylori positivity. Of the 20 cases of gastritis showed inflammatory activity, 11 showed H. Pylori positivity. H. pylori was seen in 21 cases which could be graded. Of the 15 cases of gastritis showing surface epithelial damage, 9 cases showed H. pylori positivity. Chronic inflammation was most commonly observed and 22 of the 41 cases with chronic inflammation showed H.pylori positivity. Presence of H. pylori was an useful indicator in grading of gastritis. Conclusion: Visual analogue scale is an useful indicator to histologically grade chronic gastritis and detection of H. Pylori and helps in better evaluation of patient in preventing the further progression of the disease.
\end{abstract}

Key words: Chronic superficial gastritis, H. pylori, Sydney system, Visual analogue scale

\section{Introduction}

This discovery of Helicobacter Pylori and its association with carcinogenesis has significantly changed the field, establishing new guidelines for the detection of it. However, many of these 'new' players in the field often had a limited knowledge of the morphological aspects of gastric inflammations and chronic gastritis proposed Sipponen P and Price AB [1].

The "Up-Dated Sydney System", was published in 1997 by Dixon MF [2]. Sipponen $P$ and Price $A B[1]$ in Sydney System for the classification of gastritis emphasized the importance of combining topographical, morphological, and etiological information into a schema that would help to generate reproducible and clinically useful diagnoses and it provided a helpful

Manuscript received: $8^{\text {th }}$ January 2018

Reviewed: $18^{\text {th }}$ January 2018

Author Corrected: $25^{\text {th }}$ January 2018

Accepted for Publication: $31^{\text {st }}$ January 2018 "visual analogue scale" for the grading of the histological parameters (chronic inflammation, activity, atrophy, intestinal metaplasia and H. pylori) that had been already listed in the original Sydney System. [Figure 1]

Chronic gastritis is inflammation of stomach mucosa that has as main causal factor the Helicobacter pylori with great prevalence (about $50 \%$ in world population). Has universal distribution and increases with age [3].

One in each six individuals infected by it has risk of developing ulcer; $1-3 \%$ in USA and $12 \%$ in Japan have chances to develop cancer of stomach during lifetime [4]. The public health burden of gastric cancer remains significant, and it is still the fourth in cancer incidence and the second leading cause of cancer-related mortality worldwide [5]. 
Original Research Article

The objective of this study was -

1. To assess the presence and frequency of H. pylori gastritis.
2. Grade the variables with the help of visual analogue scale to analyse chronic gastritis and prove its association with H. Pylori.

\section{Materials and Methods}

Place of study: This study was done in Department of Pathology, Dr B R Ambedkar Medical College and Hospital, Bangalore in collaboration with Department of Surgery

Type of study: A prospective study for 3 years from 2011 to 2013

Sampling methods: Biopsy was taken from a total of 50 patients with symptoms of dyspepsia

Sample collection: Biopsies were fixed in $10 \%$ formalin and histopathological slides were prepared for staining with Geimsa and confirmed with Immunohistochemical methods using paraffin blocks.

Inclusion criteria: The study included all biopsies which were done for various chronic upper abdominal symptoms like abdominal pain, dyspepsia, heartburn, nausea, vomiting and also for associated systemic manifestations like anorexia, weight loss.

Exclusion criteria: Patients with acute symptoms, patients on H. pylori eradication therapy and autolysed samples were excluded from the study.

Statistical methods: Grading of the variable were done in reference to Sydney classification as given by Aydin O et al [6] Morphological changes in all cases were studied with special reference to atrophy, dysplasia, metaplasia, neutrophilic infiltration, lymphoid follicle formation, plasma cell infiltration \& malignant changes along with identification of $\mathrm{H}$. pylori. The data was analyzed using SPSS version 20. Microsoft word and Excel have been used to generate graphs, tables.

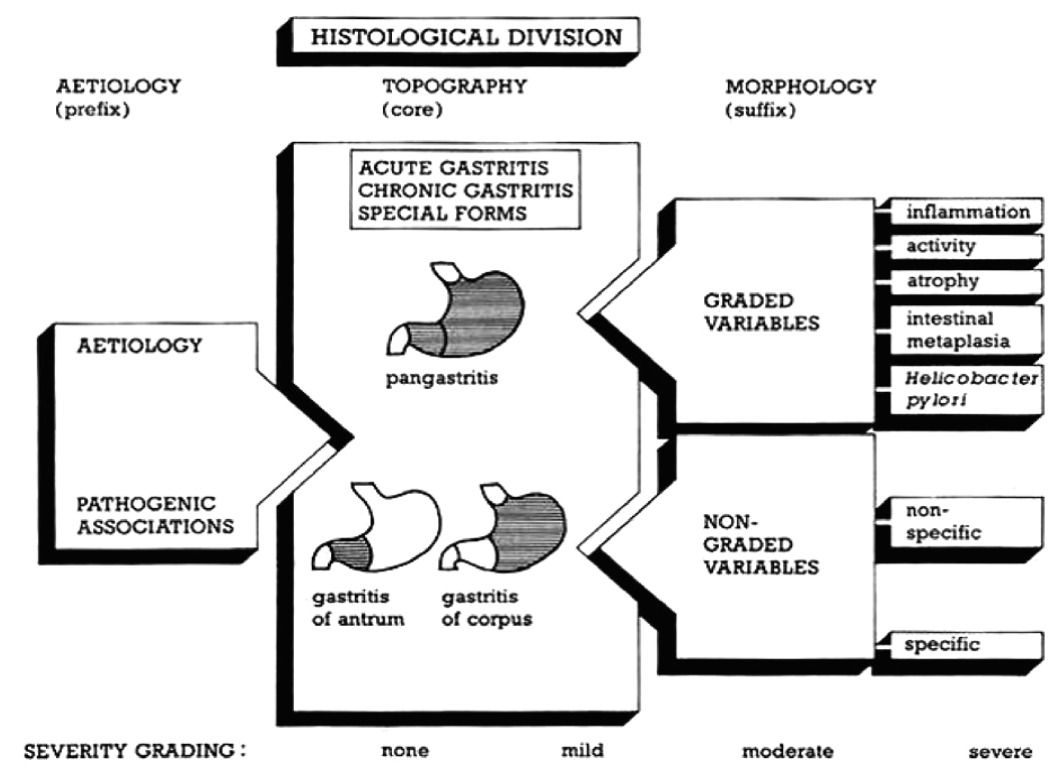

Figure-1: Sydney system of classification [2]

\section{Results}

Of the 50 cases of studied most of them had chronic H. pyloric gastritis [ $n=20(40 \%)$ ] followed by chronic gastritis with non specific features $[\mathrm{n}=18(36 \%)]$. Acute $\mathrm{H}$ pylori gastritis was seen in one case which showed dense neutrophilic infiltration with numerous $\mathrm{H}$ pylori organisms confirmed with immunohistochemistry. Most frequent site sampled for biopsy was from gastric antrum constituting 46 cases $(86.8 \%)$. It was the most frequent site for both carcinomas and gastritis with 2 cases of carcinoma at antrum. Evaluation for graded variables showed 41 cases of gastritis showing 


\section{Original Research Article}

chronic inflammation of which 22 cases showed H. Pylori positivity. Of the 20 cases of gastritis showing inflammatory activity 11 cases showed H. Pylori positivity. H. pylori was seen in 21 cases which could be graded. Of the 15 cases of gastritis showing surface epithelial damage, 9 cases showed H. pylori positivity. Chronic inflammation was most commonly observed and 22 of the 41 cases with chronic inflammation showed H.pylori positivity.

Presence of H.pylori was an useful indicator in grading of gastritis (Figure 2) Intestinal metaplasia and surface epithelial damage were seen in 55.5\% and 60\% respectively. (Table 1, Figure 3). Most frequent site sampled for biopsy was from gastric antrum constituting 46 cases $(86.8 \%)$. Of the 53 cases of studied most of them had chronic H. pyloric gastritis $[\mathrm{n}=20(44.4 \%)]$ followed by chronic gastritis with nonspecific features [n=18 (38.6\%)].

Table-1: Graded variables and its association with H. Pylori

\begin{tabular}{|c|c|c|c|}
\hline Variables & $\begin{array}{c}\text { Total } \\
{[\mathbf{5 0}]}\end{array}$ & H. Pylori positivity & Percentage \\
\hline Chronic inflammation & 41 & 22 & $53.6 \%$ \\
\hline Inflammatory activity & 20 & 11 & $55 \%$ \\
\hline Intestinal metaplasia & 9 & 5 & $55.5 \%$ \\
\hline Atrophy & 8 & 21 & $50 \%$ \\
\hline H. pylori & 21 & 9 & $100 \%$ \\
\hline Surface epithelial damage & 15 & 4 & $60 \%$ \\
\hline
\end{tabular}

Table-2: Comparative study for graded variables

\begin{tabular}{|c|c|c|c|c|}
\hline Variable & $\begin{array}{c}\text { Ahluwalia et al [11] } \\
\mathbf{( 2 0 0 1 )}\end{array}$ & $\begin{array}{c}\text { Afzal S et al [12] } \\
\mathbf{2 0 0 6}\end{array}$ & $\begin{array}{c}\text { Misra et al [13] } \\
\mathbf{( 2 0 0 7 )}\end{array}$ & $\begin{array}{c}\text { Present study } \\
\mathbf{( 2 0 1 3 )}\end{array}$ \\
\hline Inflammation & 16 & 59 & 11 & 29 \\
Mild & 12 & 25 & 19 & 12 \\
Moderate & 1 & 15 & 10 & - \\
Severe & 19 & 16 & 28 & 11 \\
\hline Activity & 03 & 10 & 08 & 13 \\
\hline Intestinal & 15 & & - & \\
\hline metaplasia & & - & & \\
\hline Lymphoid & & & & \\
\hline
\end{tabular}

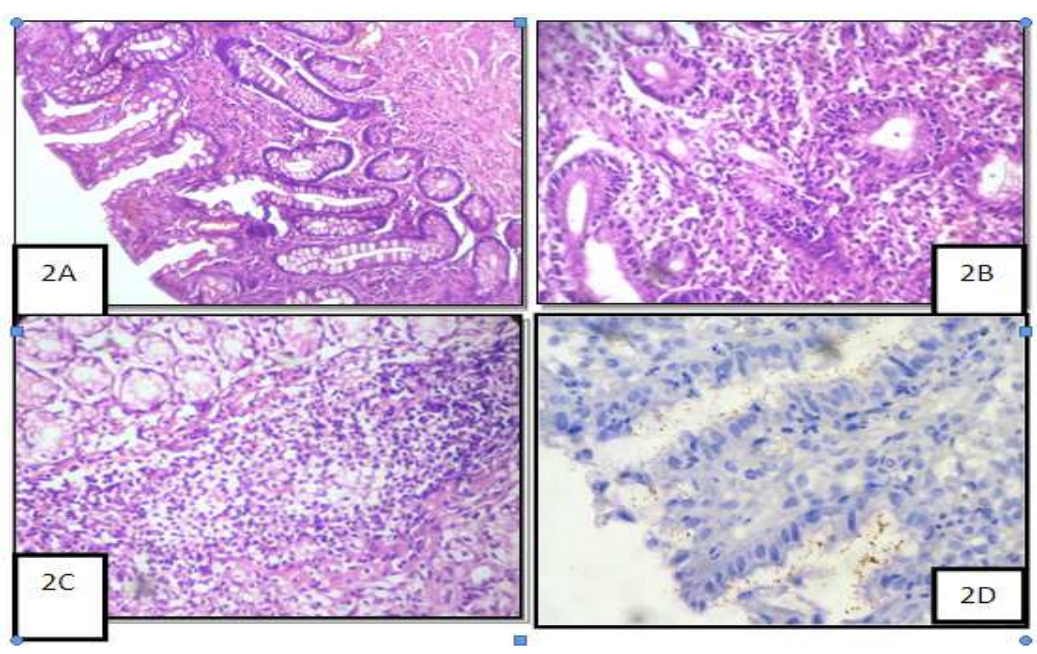

Figure-2-2A: Chronic gastritis with Intestinal metaplasia (400X) 2B. H. pyloric gastritis showing intense chronic inflammatory infiltrate (400X). 2C. Chronic H. pyloric gastritis showing Lymphoid aggregates (400X) 2D. H.Pylori Positive in IHC- Spiral Type (chromogen- DAB) 


\section{Original Research Article}

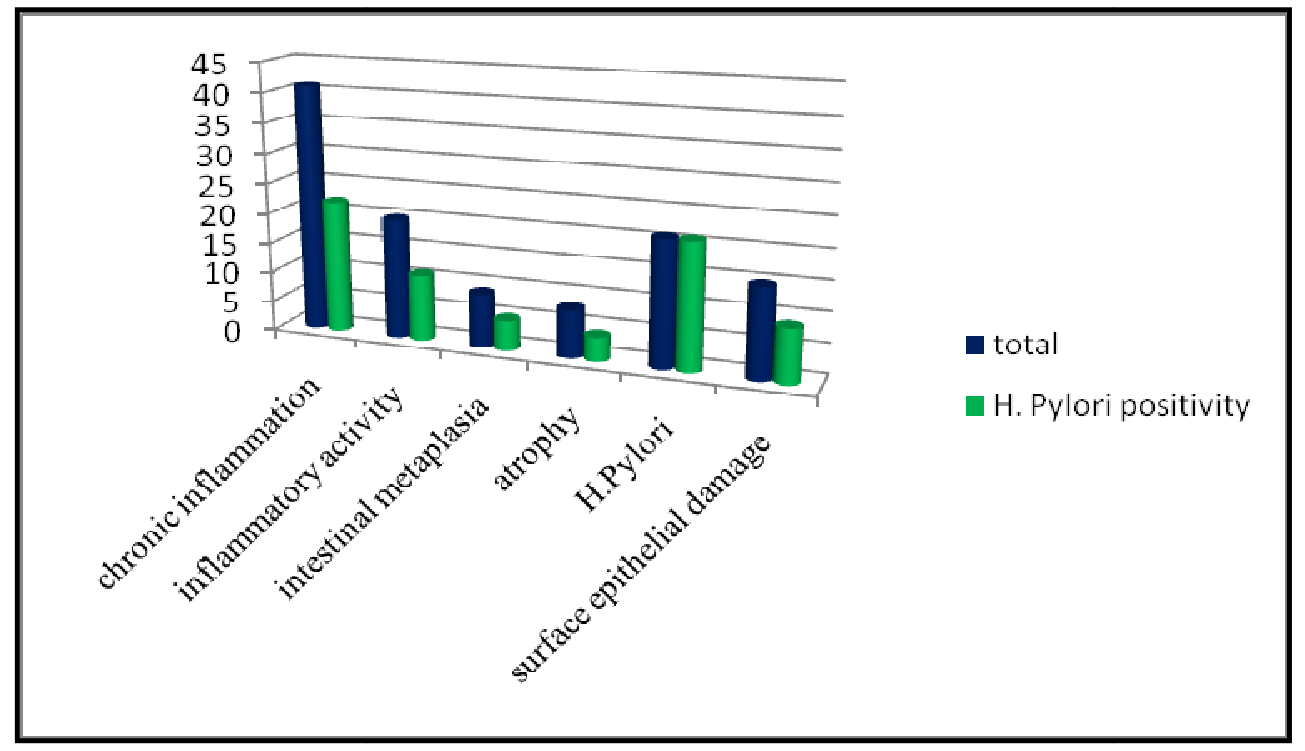

Figure-3: Graphical representation of graded variable and its association with $\mathbf{H}$. Pylori

\section{Discussion}

Carcinogenicity of Helicobacter necessitates grading the variables with visual analogue scale in accordance to Sydney system classification. Staging would convey information on the topography and extension of the gastric atrophic changes, whereas grading should represent the semi-quantitative assessment of the combined severity of both mononuclear and granulocytic inflammation.

Aydin $\mathrm{O}$ et al [6] found that visual analog scale was provided to assist in grading. A study using an early version of the visual analogue scale showed excellent interobserver agreement for the density of $\mathrm{H}$. pylori, moderate agreement for the intensity of active inflammation and poor agreement for the degree of atrophy. Rautelin H et al [7] and Dixon MF et al [2] stated neutrophil activity is an almost universal phenomenon in $\mathrm{H}$. pylori gastritis. Biopsy specimens contain neutrophils in virtually all cases of $\mathrm{H}$. pyloripositive cases if a sufficient number from both antrum and corpus is examined.

Dixon MF et al [2] observed that the normal gastric mucosa contains only individual scattered chronic inflammatory cells (mononuclear cells) in the lamina propria. Despite these limitations, the normal number of gastric mucosal mononuclear leukocytes in the lamina propria is viewed as a maximum of 2 to 5 lymphocytes, plasma cells and macrophages per high power (40 objective) microscopic field or, by another approach, two or three lymphocytes or plasma cells between foveolae (the area in which chronic inflammatory cells are most often found). Our study showed good correlation of chronic inflammation and neutrophilic activity with $\mathrm{H}$. Pylori with $51 \%$ showing mild and $58.3 \%$ moderate to marked inflammation. Similarly Sushna M [8] observed that most of the $(58.2 \%)$ of the biopsies showed moderate inflammation; $28.2 \%$ had marked inflammation and $13.6 \%$ had mild inflammation in the present study. Likewise, Park et al. [9], and Whiteman et al. [10] observed. Rugge M et al [11] opined that a useful way to gauge antral atrophy is the demonstration that the three to four gland cross sections that normally span the lower antral mucosa are reduced to two or fewer cross sections.

Rokkas $\mathrm{T}$ et al [12] stated intestinal metaplasia is generally regarded as a condition that predisposes to malignancy. With regard to other Histological Features (Nongraded Variables) Eidt S and Stolte M [13] have developed a perspective which identifies surface epithelial damage, mucous depletion, and erosions. Our study was compared with study done by Ahluwalia et al [14], These may be striking features in some cases of active H. pylori chronic gastritis. They have also mentioned that lymphoid aggregates with germinal centers are characteristic of chronic H. pylori gastritis and a hallmark of this diagnosis. The comparative analysis of different graded variables between Ahluwalia et al [14]. Afzal et al [15] et al [16] given in Table 2 .

In a study by Pruthi, S [17] H. pylori gastritis usually shows increased neutrophilic activity but can also present with increased mononuclear inflammatory infiltrate and lymphoid follicles in chronic gastritis. Intestinal metaplasia and atrophy indicates the chronicity of the disease. H. pylori were noted in the 


\section{Original Research Article}

areas away from the metaplastic gastric epithelium. Sushna Maharjan's [8] study found significant correlation was found between the presence as well as concentration of H.pylori colonization with neutrophilic and mononuclear cell infiltrate activity.

The presence of lymphoid follicles was one of the strong indicators for $H$. pylori infection. The association was demonstrated in a study by Pruthietal [17] which showed H. pylori colonizationin $55.2 \%$ cases with lymphoidfollicles, Dhakwa et al [18] had 6 cases with lymphoid follicles and $\mathrm{H}$. pylori was positive in all cases and Palaniappan et al [19] where Lymphoid aggregates were significantly more frequent in $\mathrm{H}$. pylori positive cases $(87.5 \%)$. This is in contrast to the study conducted by Amarapurkar et al [20] which did not prove statistical association of lymphoid aggregated with $\mathrm{H}$. Pylori likewise our study showed lymphoid aggregates in $26 \%$ cases of $\mathrm{H}$. Pyloric gastritis.

In the present study, of the 50 cases of studied most of them had chronic H. pyloric gastritis [ $n=20(44.4 \%)]$ followed by chronic gastritis with non specific features $[\mathrm{n}=18(38.6 \%)] .25$ of the 53 cases showed positivity for $\mathrm{H}$. pylori which was confirmed with IHC of which $20(32.7 \%)$ were chronic H. pyloric gastritis. 4 cases which showed carcinoma also were positive for $\mathrm{H}$. pylori. Our study showed the presence of chronic inflammation which ranged from moderate to marked along with presence of $\mathrm{H}$. Pylori were the strongest indicators in the graded variable for the presence of chronic gastritis.

The Sydney system classifies chronic gastritis on the basis of topography, morphology, and, when possible, etiology, into three broad categories: acute, chronic, and special (or distinctive). This system provides guidelines for generating systematic and uniform diagnostic reports. The goal of the Sydney System is to make gastric biopsy pathology reporting consistent, so that clinical studies can be performed and evaluated in a meaningful manner [21].

Though the limitations in the study was the inability to obtain biopsy from the intended topographic sites according to the Sydney system for $H$. pylori, neutrophilic infiltration, MNC infiltrate, gastric atrophy or Intestinal Metaplasia, the significant association of H. Pylori and co existent inflammation with chronic gastritis was noted. An improved sample size could provide a better correlation to the statistical analysis of this study.

\section{Conclusion}

Gastric biopsy brings important practical supplement to endoscopic examination in revealing the presence of $\mathrm{H}$. pylori. Our study also highlighted the association of Helicobacter Pylori in patients with functional dyspepsia and proved the significance of visual analogue scale along with Sydney Classification in Chronic gastritis. This study also shows good correlation of all variables of the visual analogue scale with H. Pylori. Visual analogue scale is a good indicator in assessing chronic gastritis and thereby prevent the progression of disease to carcinogenesis

Acknowledgment: Deep sense of gratitude to Dr. Manjunatha Y. A for his immense help and guidance during this study. I thank Dr Gitanjali M.M for her help during the manuscript preparation. Funding: Nil, Conflict of interest: None initiated
Permission from IRB: Yes

\section{References}

1. Sipponen P, Price AB. The Sydney System for classification of gastritis 20 years ago. J Gastroenterol Hepatol. 2011 Jan; 26 Suppl 1:31-4. doi: 10.1111/j. 1440-1746. 2010.06536.x.

2. Dixon MF, Genta RM, Yardley JH, Correa P. Classification and grading of gastritis. The updated Sydney System. International Workshop on the Histopathology of Gastritis, Houston 1994. Am J Surg Pathol. 1996 Oct;20(10):1161-81.

3. Miszputen SJ. Guia de Gastroenterologia. 2a. ed. São Paulo: Manole, 2006.

4. Graham D. Tratado de Medicina Interna. São Paulo, Saunders Elsevier, 2005.

5. Adamu MA, Weck MN, Gao L, Brenner $\mathrm{H}$. Incidence of chronic atrophic gastritis: systematic review and meta-analysis of follow-up studies. Eur $\mathbf{J}$ Epidemiol. $2010 \mathrm{Jul}$; 25(7):439-48. doi: 10.1007/s 10654-010-9482-0. Epub 2010 Jun 29.

6. Aydin O, Egilmez R, Karabacak T, Kanik A. Interobserver variation in histopathological assessment of Helicobacter pylori gastritis. World J Gastroenterol. 2003 Oct; 9(10):2232-5.

7. Rautelin H, Blomberg B, Fredlund H, Järnerot G, Danielsson D. Incidence of Helicobacter pylori strains 
Original Research Article

activating neutrophils in patients with peptic ulcer disease. Gut. 1993 May; 34 (5):599-603.

8. Zhuang Z, Wang S. Corrigendum to Histone Methyltransferase aflrmt A gene is involved in the morphogenesis, mycotoxin biosynthesis, and pathogenicity of Aspergillus flavus" [Toxicon 127 (2017, Mar 1) 112-121]. doi: 10.1016/j.toxicon.2017. 01.013. Epub 2017 Jan 19. Toxicon. 2017 Aug;134:64. doi: 10.1016/j.toxicon.2017.05.026.

9. Park J, Kim MK, Park SM. Influence of Helicobacter pylori colonization on histological grading of chronic gastritis in Korean patients with peptic ulcer. Korean J Intern Med. 1995; 10 (2): 125-129.

10. Witteman EM, Mravunac M, Becx MJ, Hopman WP, Verschoor JS, Tytgat GN et al. Improvement of gastric inflammation and resolution of epithelial damage one year after eradication of Helicobacter pylori. JCP,1995; 48(3):250-256.

11. Rugge M, Correa P, Dixon MF, Fiocca R, Hattori T, Lechago J, Leandro G, Price AB, Sipponen P, Solcia E, Watanabe H, Genta RM. Gastric mucosal atrophy: interobserver consistency using new criteria for classification and grading. Aliment Pharmacol Ther. 2002 Jul;16(7):1249-59.

12. Rokkas T, Filipe MI, Sladen GE. Detection of an increased incidence of early gastric cancer in patients with intestinal metaplasia type III who are closely followed up. Gut. 1991 Oct; 32(10): 1110-1113

13. Eidt S, Stolte M. Prevalence of lymphoid follicles and aggregates in Helicobacter pylori gastritis in antral and body mucosa. J Clin Pathol 1993;46:832-835.
14. Patwari AK, Anand VK, Malhotra V, Balani B, Gangil A, Jain A, Kapoor G. Brush cytology: an adjunct to diagnostic upper GI endoscopy. Indian J Pediatr. 2001 Jun;68(6):515-8.

15. Afzal S, Ahmad M, Mubarik A, Saaed F, Rafi S, Saleem N, Hussain A. Morphological Spectrum Of Gastric Lesions - Endoscopic Biopsy Findings. Pak Armed Forces Medical J 2006;2:1-9.

16. Misra V, Misra SP, Singh MK, Singh PA, Dwivedi M. Prevalence of $\mathrm{H}$. pylori in patients with gastric cancer. Indian J Pathol Microbiol.2007Oct;50(4):702-7.

17. Pruthi S, Nirupama M, Chakraborti S. Evaluation of gastric biopsies in chronic gastritis: Grading of inflammation by Visual Analogue Scale. Med J DY Patil Univ 2014;7:463-7.

18. Dhakhwa R, Acharya IL, Shrestha HG, Joshi DM, Lama S, Lakhey M. Histopathologic study of chronic antral gastritis. J Nepal Health Res Counc. 2012 Jan;10 (1): 57-60.

19. Palaniappan V, Venkatraman Janarthanam and Swaminathan K. (2016). Histomorphological profile of Gastric antral mucosa in Helicobacter associated gastritis. Int. J. Curr. Res. Med. Sci. 2(4): 22-28.

20. Amarapurkar AD, Prabhu SR, Amarapurkar DN. Histological spectrum of lymphoid follicles and aggregates in Helicobacter pylori gastritis. Trop Gastroenterol. 1997 Jan-Mar;18(1):22-3.

21. Carrasco, G., \& Corvalan, A. H. Helicobacter pylori-Induced Chronic Gastritis and Assessing Risks for Gastric Cancer. Gastroenterology Research and Practice, 2013, 393015.

\section{How to cite this article?}

Priyadarshini M M, Gitanjali M. M, Manjunatha Y. A. Significance of histologic grading using visual analogue scale in chronic gastritis. Trop J Path Micro 2018;4(1):82-87. doi: 10.17511/jopm.2018.i1.15. 